\title{
Modelling the effects of row configuration on sorghum yield reliability in north-eastern Australia
}

\author{
Jeremy Whish ${ }^{\mathrm{A}, \mathrm{I}}$, Giles Butler ${ }^{\mathrm{B}}$, Michael Castor ${ }^{\mathrm{C}}$, Shayne Cawthray ${ }^{\mathrm{D}}$, Ian Broad ${ }^{\mathrm{E}}$, \\ Peter Carberry ${ }^{\mathrm{A}}$, Graeme Hammer ${ }^{\mathrm{E}, \mathrm{F}}$, Greg McLean $^{\mathrm{E}}$, Richard Routley ${ }^{\mathrm{G}}$, and Steven Yeates ${ }^{\mathrm{H}}$ \\ ${ }^{A}$ CSIRO Sustainable Ecosystems, Agricultural Production Systems Research Unit, \\ PO Box 102, Toowoomba, Qld 4350, Australia. \\ ${ }^{B}$ NSW Primary Industries, Tamworth Centre for Crop Improvement, Calala Lane, \\ Tamworth, NSW 2340, Australia. \\ ${ }^{\mathrm{C}}$ Michael Castor and Associates, 48 Winton Street, Goondiwindi, Qld 4390, Australia.

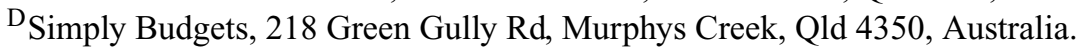 \\ ${ }^{\mathrm{E}}$ Qld Department of Primary Industries, Agricultural Production Systems Research Unit, \\ PO Box 102, Toowoomba, Qld 4350, Australia. \\ ${ }^{\mathrm{F}}$ School of Land and Food Sciences, The University of Queensland, Brisbane, Qld 4072, Australia. \\ ${ }^{\mathrm{G}}$ Qld Department of Primary Industries, Agricultural Production Systems Research Unit, \\ Roma Research Station, PO Box 308, Roma, Qld 4455, Australia. \\ ${ }^{\mathrm{H}}$ CSIRO Plant Industry, 20 Vanderlin Dve, Berrimah, NT 0828, Australia. \\ ${ }^{\mathrm{I} C}$ Corresponding author. Email: jeremy.whish@csiro.au
}

\begin{abstract}
In recent years, many sorghum producers in the more marginal $(<600 \mathrm{~mm}$ annual rainfall $)$ cropping areas of Queensland and northern New South Wales have used skip row configurations in an attempt to improve yield reliability and reduce sorghum production risk.

This paper describes modifications made to the APSIM sorghum module to account for the difference in water usage and light interception between alternative crop planting configurations, and then demonstrates how this new model can be used to quantify the long-term benefits of skip sorghum production.

Detailed measurements of light interception and water extraction from sorghum crops grown in solid, single and double skip row configurations were collected from on-farm experiments in southern Qld and northern NSW. These measurements underpinned changes to the APSIM-Sorghum model so that it accounted for the elliptical water uptake pattern below the crop row and the reduced total light interception associated with skip row configurations.

Long-term simulation runs using long-term weather files for locations near the experimental sites were used to determine the value of skip row sorghum production as a means of maintaining yield reliability. These simulations showed a trade-off between long-term average production (profitability) and annual yield reliability (risk of failure this year). Over the long term, the production of sorghum in a solid configuration produced a higher average yield compared with sorghum produced in a skip configuration. This difference in average yield is a result of the solid configuration having a higher yield potential compared with the skip configurations. Skip configurations limit the yield potential as a safeguard against crop failure. To achieve the higher average yield in the solid configuration the producer suffers some total failures. Skip configurations reduce the chance of total failure by capping the yield potential, which in turn reduces the long-term average yield. The decision on what row configuration to use should be made tactically and requires consideration of the starting soil water, the soil's plant-available water capacity (PAWC), and the farm family's current attitude to risk.
\end{abstract}

Additional keywords: sorghum, simulation modelling, APSIM, light interception.

\section{Introduction}

The production and yield reliability of rain-fed grain sorghum in semi-arid tropical and subtropical environments of Australia is affected by the sporadic nature of rainfall, and decreasing rainfall gradients from both north to south and east to west during the growing season (Myers et al. 1986). To compensate for seasonal variability, the spatial pattern of the sorghum stand is manipulated to reduce risk. In north-eastern Australia, significant responses to plant arrangement have been observed in sorghum by varying row spacing between 
$0.3 \mathrm{~m}$ and $4 \mathrm{~m}$ (Thomas et al. 1981; Holland and McNamara 1982; Fukai and Foale 1988). Responses to varying plant density, however, were not great due to compensation among yield components (Wade and Douglas 1990). Since the time of these experiments, most sorghum has been grown in 1-m rows, which was considered as the best compromise in a region where soil moisture and in-crop rainfall are variable. It was also noted, when selecting the 1-m row spacing, that under water critical conditions, wider rows $(>1 \mathrm{~m})$ had higher yields compared with narrow rows $(<1 \mathrm{~m})$ at the same population (Wade and Douglas 1990).

Row spacing can have a significant effect on yield (Phillips and Norman 1962) and this can be exacerbated if weed control is poor (Myers and Foale 1981; Holland and McNamara 1982). The decision on which row spacing to use is generally a compromise, especially in dryland farming systems. If resources are non-limiting then plants grown close together in narrow row spacing, will achieve canopy closure early in the season and maximise light interception, productivity, and reduce weed emergence (Foale and Coates 1980; Holland and McNamara 1982). In dryland agriculture, resources are rarely non-limiting, so in order to ration the resource pool, row spacing is widened while maintaining plant population. This increases competition within the row (Blum and Naveh 1976) while providing additional resources in the space between rows. Within-row competition early in the plant's life cycle limits the supply of water and nutrients to the plant, reducing leaf area and root development, and delays access to the interrow reserves of water and nutrients until later in the crop's life cycle (Wade et al. 1991).

The availability of resources depends on the capacity of the soil to store resources, and the amount and the timing of resource replenishment, which are subject to seasonal variability. Simulation modelling is one approach to assessing the effect of row spacing on resource availability under varying seasonal conditions. Wade et al. (1991) used a combination of regression modelling and simulation modelling to assess row spacing between 0.3 and $1.5 \mathrm{~m}$ for sorghum crops. This work showed an advantage of wide rows as a means of avoiding risk by achieving yield stability. Crops produced in a wide row configuration had a lower yield potential, but a narrower yield distribution, compared with crops with a $0.3-\mathrm{m}$ or $1-\mathrm{m}$ row spacing.

At the time of Wade etal. (1991), a substantial research problem within Australian sorghum crops was poor emergence and stand uniformity. More recently, changes in sowing equipment have improved the uniformity of sorghum stands and with this, the use of row spacing as a means of managing climate variability is being adopted (Butler et al. 2001; Routley et al. 2003). Before simulation analysis could be undertaken, enhancement of the current sorghum models to simulate growth and water use in wide rows was required.

Sorghum crops in NE Australia are grown on a common row spacing of $1 \mathrm{~m}$ and this is generally referred to as solid configuration. To reduce risk and improve yield reliability,
2 other configurations are often used. These are single skip, where 2 rows are planted 1-m apart and every third row is skipped leaving a 2-m gap between twin rows; and double skip, which is similar to single skip, but every third and fourth row are skipped leaving a 3-m gap between twin rows. Other row configurations are used in the sorghum-growing areas of north-eastern Australia, including ultra wide where every second row is skipped, and ultra narrow where the row spacing is reduced to $50 \mathrm{~cm}$. However, the configurations discussed in this paper will refer to those most commonly used: 'solid', 'single', and 'double'.

This paper describes modifications made to the sorghum crop model (in the APSIM system simulation platform, Keating et al. 2003) to enable it to simulate sorghum crops grown in skip row configurations. We then test the new model against detailed field trials established in the sorghumproduction areas of northern New South Wales and southern Queensland and present long-term simulations comparing risks for different sorghum row configurations at those locations.

\section{Methods}

\section{APSIM simulations}

The current APSIM-Sorghum model was developed from the QSORG model (Hammer and Muchow 1991), with features of the AUSIM model (Carberry and Abrecht 1991), and has been recently adapted into the APSIM-generic crop template (Wang et al. 2002). The current sorghum module estimates light interception with a whole plant leaf area approach (Hammer et al. 1993). This method of estimating light interception is analogous to the Beer-Lambert law, and assumes a random horizontal distribution of leaf area. In simulating skip row sorghum the assumption of a horizontally distributed leaf area holds only for the blocks of ground with canopy cover. To account for this the equation for calculating the percentage green cover of the plant is changed from Eqn 1 to Eqn 2:

$$
\% \text { green cover }=1-e^{-k l}
$$

where $k$ is the extinction coefficient of the crop at that row spacing and $l$ is the leaf area index:

$$
\% \text { green cover }=\frac{1-e^{-k l s}}{s}
$$

where $k$ is the extinction coefficient of the crop at that row spacing, $l=$ is the leaf area index, and $s$ is the skip index ( 1 for no skipped rows 'Solid', 1.5 for 1 skipped row 'Single', and 2 for 2 skipped rows 'Double'). This accounts for the concentration of the canopy leaf area around the rows and for gaps in the canopy as the skip index increases. This method of modelling discontinuous canopies is based on that described by Jackson and Palmer (1979) and Charles-Edwards and Lawn (1984), and is supported by measurements of light interception in these systems (Routley et al. 2003).

The second change to the APSIM sorghum module was a modification to the root expansion front. The existing method of root expansion in the soil profile is described by Robertson and Fukai (1994), and includes only a uni-directional approach that has roots filling soil layers and expanding only in a downward direction. With the skip configuration, the wide gap between plants meant that root expansion needed to be multi-directional, allowing time for the roots to reach the centre of the skip rows. Experimental results (Routley et al. 2003) showed that the root expansion front could be described by a semicircular front expanding from the base of the plant at a rate of $2 \mathrm{~cm}$ per day in all directions (McLean et al. 2003). 
Table 1. Initial parameters used for validation of the skip row sorghum model

PAWC, Plant-available water capacity to $1.8 \mathrm{~m}$. Soil reference number from Dalgliesh and Foale (1998)

\begin{tabular}{|c|c|c|c|c|c|c|c|c|}
\hline Site & & $\begin{array}{l}\text { Row spacing } \\
\text { (m) }\end{array}$ & $\begin{array}{l}\text { Sow } \\
\text { date }\end{array}$ & $\begin{array}{l}\text { PAWC } \\
(\mathrm{mm})\end{array}$ & $\begin{array}{c}\text { Starting } \\
\text { water }(\%)\end{array}$ & $\begin{array}{c}\text { Starting } \\
\mathrm{N}(\mathrm{kg} / \mathrm{ha})\end{array}$ & $\begin{array}{l}\text { Plant density } \\
\text { (plants } / \mathrm{m}^{2} \text { ) }\end{array}$ & $\begin{array}{l}\text { Fertile tiller no. } \\
\quad\left(\text { tillers } / \mathrm{m}^{2}\right)\end{array}$ \\
\hline \multirow[t]{3}{*}{ Moree 1999 Soil ref \# 59} & Solid & 1 & 28/09/99 & 234 & 99 & 589.9 & 4.5 & 1.1 \\
\hline & Single & 1 & 28/09/99 & 234 & 99 & 589.9 & 4.2 & 0.8 \\
\hline & Double & 1 & $28 / 09 / 99$ & 234 & 99 & 589.9 & 4.4 & 0.5 \\
\hline \multirow[t]{3}{*}{ Billa Billa 2000 Soil ref \# 36} & Solid & 1 & $13 / 11 / 00$ & 304 & 43 & 217 & 8.5 & 0 \\
\hline & Single & 1 & $13 / 11 / 00$ & 304 & 55 & 217 & 8.2 & 0.04 \\
\hline & Double & 1 & $13 / 11 / 00$ & 304 & 75 & 217 & 7.5 & 0.06 \\
\hline \multirow[t]{2}{*}{ Billa Billa 2001 Soil ref \# 36} & Solid & 1 & $05 / 12 / 01$ & 194.5 & 73 & 552 & 7.8 & 0 \\
\hline & Double & 1 & $05 / 12 / 01$ & 194.5 & 73 & 552 & 7.6 & 0 \\
\hline \multirow[t]{3}{*}{ Meandarra 1998 Soil ref \# 93} & Solid & 1 & 06/01/99 & 136.5 & 62 & 344 & 6.1 & 0.15 \\
\hline & Single & 1 & $06 / 01 / 99$ & 136.5 & 91 & 291 & 6.4 & 0.23 \\
\hline & Double & 1 & $06 / 01 / 99$ & 136.5 & 68 & 194 & 5.4 & 0.06 \\
\hline \multirow[t]{4}{*}{ Meandarra 1999 Soil ref \# 93} & Solid & 1 & $29 / 09 / 99$ & 136.5 & 98 & 192 & 8.7 & 0.26 \\
\hline & Single & 1 & $29 / 09 / 99$ & 136.5 & 96 & 192 & 7.8 & 0.24 \\
\hline & Double & 1 & 29/09/99 & 136.5 & 100 & 192 & 4.7 & 0.68 \\
\hline & Double & 1 & $29 / 09 / 99$ & 136.5 & 100 & 192 & 7.5 & 0.28 \\
\hline \multirow[t]{2}{*}{ Meandarra 2000 Soil ref \# 93} & Solid & 1 & $05 / 12 / 00$ & 133.5 & 72 & 349 & 6.6 & 0.26 \\
\hline & Single & 1 & $05 / 12 / 00$ & 133.5 & 72 & 349 & 5.5 & 0.4 \\
\hline \multirow[t]{3}{*}{ Croppa Creek 1999 Soil ref \# 53} & Solid & 1 & $20 / 10 / 99$ & 235 & 48 & 154.1 & 6.1 & 0 \\
\hline & Single & 1 & $20 / 10 / 99$ & 235 & 48 & 154.1 & 6 & 0 \\
\hline & Double & 1 & $20 / 10 / 99$ & 235 & 48 & 154.1 & 5.8 & 0 \\
\hline \multirow[t]{3}{*}{ Croppa Creek 2000 Soil ref \# 53} & Solid & 1 & $06 / 11 / 00$ & 191.5 & 84.6 & 225 & 7.7 & 0.25 \\
\hline & Single & 1 & $06 / 11 / 00$ & 191.5 & 84.6 & 225 & 7.2 & 0.11 \\
\hline & Double & 1 & $06 / 11 / 00$ & 191.5 & 84.6 & 225 & 7.5 & 0.18 \\
\hline \multirow[t]{3}{*}{ Boggabilla 1998 Soil ref \# 101} & Solid & 1 & $16 / 12 / 98$ & 181 & 48 & 134 & 4.8 & 0.5 \\
\hline & Single & 1 & $16 / 12 / 98$ & 181 & 48 & 134 & 6.7 & 0.7 \\
\hline & Double & 1 & $16 / 12 / 98$ & 181 & 48 & 134 & 2.9 & 0.6 \\
\hline \multirow[t]{3}{*}{ Bungunya 2001 Soil ref \# n.a. ${ }^{\mathrm{A}}$} & Solid & 1 & $28 / 09 / 01$ & 202 & 68 & 307.7 & 5 & 0.25 \\
\hline & Single & 1 & $28 / 09 / 01$ & 202 & 68 & 307.7 & 4.2 & 0.28 \\
\hline & Double & 1 & $28 / 09 / 01$ & 202 & 68 & 307.7 & 4.2 & 0 \\
\hline
\end{tabular}

${ }^{\text {A }}$ Soil reference not available in Dalgliesh and Foale (1998).

\section{Model testing}

APSIM-Sorghum (V3.1) was tested against observed data collected from 4 detailed on-farm research experiments (Routley et al. 2003) and 6 on-farm monitoring sites (Butler et al. 2001) in NE Australia. For each observed dataset, the APSIM skip row sorghum model was parameterised as described in Table 1. Soil characterisation data from Dalgliesh and Foale (1998) were used to parameterise the soil at each site. The number of fertile tillers presented in Table 1 was measured at the experimental sites.

\section{Long-term simulations}

Long-term simulations were conducted for each experimental site using meteorological data from the nearest meteorological station (Table 2). The starting soil water for each site was varied as a percentage of PAWC, giving simulations a starting soil water of 30,60 , and $90 \%$, each year at each site. Soil nitrogen was set to be non-limiting (Table 2) and the sowing date was standardised at 15 November in all years. For consistency the sowing density was the same at each site ( 75000 plants/ha) and the number of fertile tillers set to $1,0.5$, and 0 for the solid, single, and double skip row configurations respectively. The values used for the fertile tiller number were estimated from experience and considered the sowing density, time of sowing and geographic location of the sites. A sensitivity analysis was conducted to assess the effect of tiller numbers on the long-term distribution of yields from the 3 row spacing configurations. The main effect of locking fertile tiller number to 1 across all configurations was a $0.6 \%$ increase to the maximum $10 \%$ of yields for the double skip crop (data not shown).

The long-term simulations were designed as a factorial experiment with starting water as one factor, row configuration as a second factor, and the 100-year simulation as replication. This design enabled the yield outputs to be analysed by analysis of variance to assess the interaction between starting water and row spacing.

\section{Statistics}

Statistical analysis was conducted using the linear regression and analysis of variance routines of the statistical software package $\mathrm{R}$ version 1.61 ( $\mathrm{R}$ Development Core Team 2004).

\section{Results}

\section{Model validation}

Data used for testing the model were from on-farm experiments conducted in southern Qld and northern NSW. Overall the model was able to explain $85 \%$ of the yield variation and $75 \%$ for biomass variation (Fig. 1). The data 
Table 2. Initial parameters used for long-term simulations Soil water and nitrogen were allocated from the surface layers down

\begin{tabular}{|c|c|c|c|c|}
\hline $\begin{array}{l}\text { Starting } \\
\text { soil water } \\
(\% \text { PAWC) }\end{array}$ & $\begin{array}{l}\text { Row } \\
\text { spacing } \\
(\mathrm{m})\end{array}$ & $\begin{array}{l}\text { PAWC } \\
(\mathrm{mm})\end{array}$ & $\begin{array}{c}\text { Starting } \\
\text { water } \\
(\mathrm{mm})\end{array}$ & $\begin{array}{c}\text { Starting } \\
\mathrm{N} \\
(\mathrm{kg} / \mathrm{ha})\end{array}$ \\
\hline \multicolumn{5}{|c|}{ Billa Billa } \\
\hline 30 & 1 & 201 & 80.4 & 201.06 \\
\hline 60 & 1 & 201 & 160.8 & 201.06 \\
\hline 90 & 1 & 201 & 198.5 & 201.06 \\
\hline \multicolumn{5}{|c|}{ North Star } \\
\hline 30 & 1 & 238 & 79.4 & 201.55 \\
\hline 60 & 1 & 238 & 158.8 & 201.55 \\
\hline 90 & 1 & 238 & 235.1 & 201.55 \\
\hline \multicolumn{5}{|c|}{ Bungunya } \\
\hline 30 & 1 & 202 & 67.4 & 199.1 \\
\hline 60 & 1 & 202 & 134.8 & 199.1 \\
\hline 90 & 1 & 202 & 198.7 & 199.1 \\
\hline \multicolumn{5}{|c|}{ Moree } \\
\hline 30 & 1 & 234 & 77.9 & 199.96 \\
\hline 60 & 1 & 234 & 155.8 & 199.96 \\
\hline 90 & 1 & 234 & 231.2 & 199.96 \\
\hline \multicolumn{5}{|c|}{ Boggabilla } \\
\hline 30 & 1 & 178 & 59.4 & 199.9 \\
\hline 60 & & 178 & 118.8 & 199.9 \\
\hline 90 & 1 & 178 & 174.2 & 199.9 \\
\hline \multicolumn{5}{|c|}{ Meandarra } \\
\hline 30 & 1 & 133 & 44.4 & 201.5 \\
\hline 60 & 1 & 133 & 88.9 & 201.5 \\
\hline 90 & 1 & 133 & 131.4 & 201.5 \\
\hline
\end{tabular}

described by Fig. 1 include results from solid, single, and double row configurations. Irrespective of the row spacing, the distribution of the data is generally along the $1: 1$ line.
Confidence interval lines calculated at $2 \times$ s.e. encase the $1: 1$ line, suggesting that there is no significant variation between the regression line and the $1: 1$ line.

Simulated soil water for the 4 detailed sites correlated well with the observed soil water data (Figs 2-5). The large rainfall events that occurred around Day 90 at North Star (Fig. 2) and Billa Billa (Fig. 3) were adequately represented in the simulated soil water data. The bars on the observed points show the distribution of the observed replicates and the degree of variation observed in these soils (Fig. 3). Despite the high degree of variation in the soil, the modelled line follows the observed data well at all sites over the 2 years.

The ability of the model to predict leaf area was adequate. The LAI results from Billa Billa (Fig. 3), however, do not correlate well with the observed data. Accurate simulation of LAI is notoriously difficult. The good correlations between the observed and simulated water use and the accurate prediction of flowering date (data not shown) and yield were the key indices that the model was tested against. The remaining 2 sites show a good correlation between the observed and the simulated LAI points (Figs 4 and 5)

The ability of the model to predict commercial crops grown in different row configurations is presented in Fig. 6. The results show that the model predicted the differences between the row configurations well with double skip sorghum, having a lower yield compared with solid in productive seasons and a higher yield during the marginal seasons with a low productive potential. The model predicted crop yield within the range of observed yield for most sites. At North Star 1999 the yield (Fig. 6b) and biomass (data not shown) were over-estimated, but the trend was similar to the observed data. This difference is likely a result of the initial
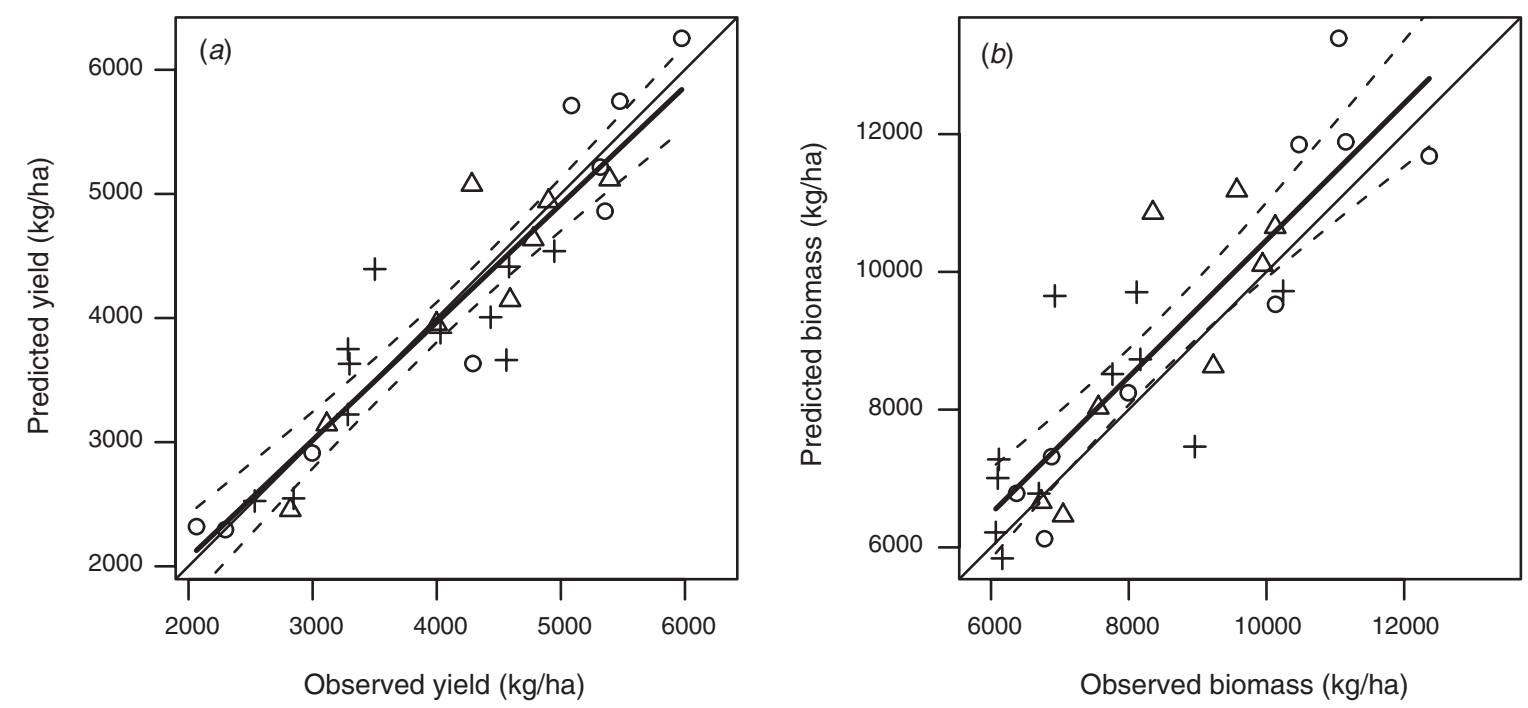

Fig. 1. Predicted $v$. observed $(a)$ yield and $(b)$ biomass at physiological maturity for 10 on-farm experiments (Table 1 ). The solid diagonal line is the 1:1 line, the bold line is the linear regression, and the broken lines are the $95 \%$ confidence limits. Yield: $R^{2}=0.85, y=0.95 x+318$. Biomass: $R^{2}=0.75, y=0.99 x+951$. $O$, Solid configuration; $\Delta$, single configuration; + , double configuration. 

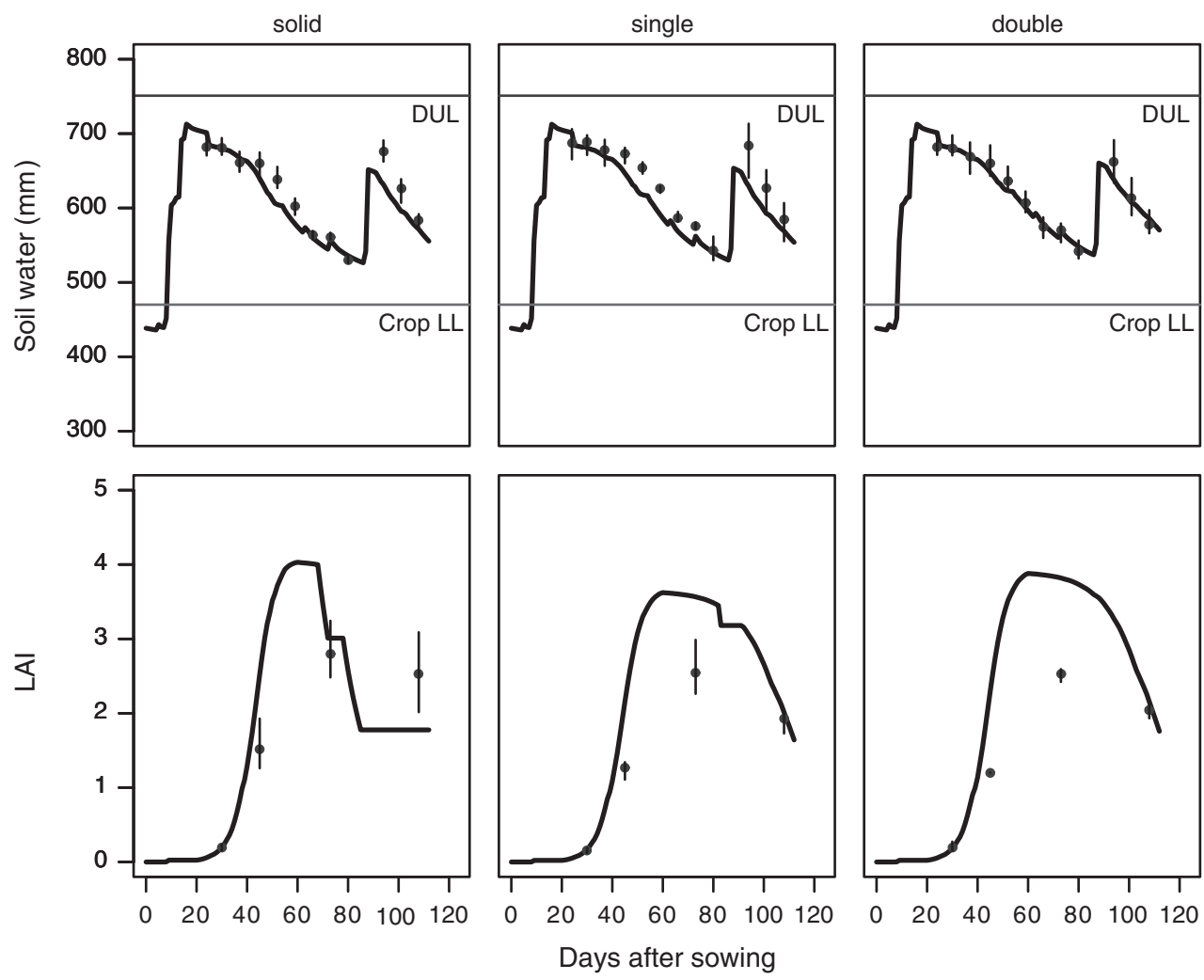

Fig. 2. Observed (points) and simulated (line) soil water and leaf area index (LAI) for solid, single, and double skip configurations at North Star 2001. Horizontal lines indicate crop lower limit (Crop LL) and the soil's drained upper limit (DUL). Vertical bars indicate the range of the observed data points.

soil parameters for this site being high. Measurements of drained upper limit, bulk density, and crop lower limit were not taken for this specific field and the difference between the observed and predicted yield was removed when a reduced water-holding capacity (PAWC) was used (data not shown) to initialise the model.

\section{Long-term simulations}

Starting soil water and row configuration (skip) both significantly affected final yield at each site (Table 3). At 4 of the 6 sites a significant interaction occurred between starting water and skip configuration. The 2 sites that did not show a significant interaction between starting water and row configuration were the 2 sites with the lowest PAWC (Table 2). The lack of interaction at these sites is a result of the limited soil water-holding capacity, which restricted the potential yield of the solid crops even with $90 \%$ starting water. The yield difference between double and single skip crops with $90 \%$ starting water on shallow soils is less than the equivalent difference on soils with a higher water-holding capacity (Fig. 7). Yield in solid configuration is much higher than in either the double or single skip configurations on soils with $238 \mathrm{~mm}$ PAWC, and single and solid yields are similar when sown with low starting moisture.
The long-term mean simulated yield of crops grown in a solid configuration over a range of starting moistures is higher than the average of double skip, and higher than or equal to single skip (Fig. 7, Table 3). However, the average values mask the results for individual occasions when row configuration influenced the chance of finishing the crop (Table 4). The simulations conducted with low starting water highlight the value of the skip configurations by enhancing chances of finishing the crop. Of the 100 years simulated with $30 \%$ starting water, the skip configurations successfully matured between 17 and 24 more crops than the solid configuration (Table 4). Further, when comparing the skip configurations with solid, it is important to determine how often a skip crop will out-yield a solid crop. Although on average the solid configuration will out-yield skip crops (Fig. 7), there were numerous years when the yield from skip configurations was greater than or equal to the solid yield (Table 5). The influence of starting water and soil waterholding capacity is important, but in general, with $30-60 \%$ soil water-holding capacity available at planting, skip will out-yield solid $50 \%$ of the time. If the profile is $90 \%$ full at sowing and the soil has a PAWC greater than $200 \mathrm{~mm}$, then the ratio of skip over solid shifts from 50-50 to approximately 40-60. Crops produced in a skip configuration will out-yield 

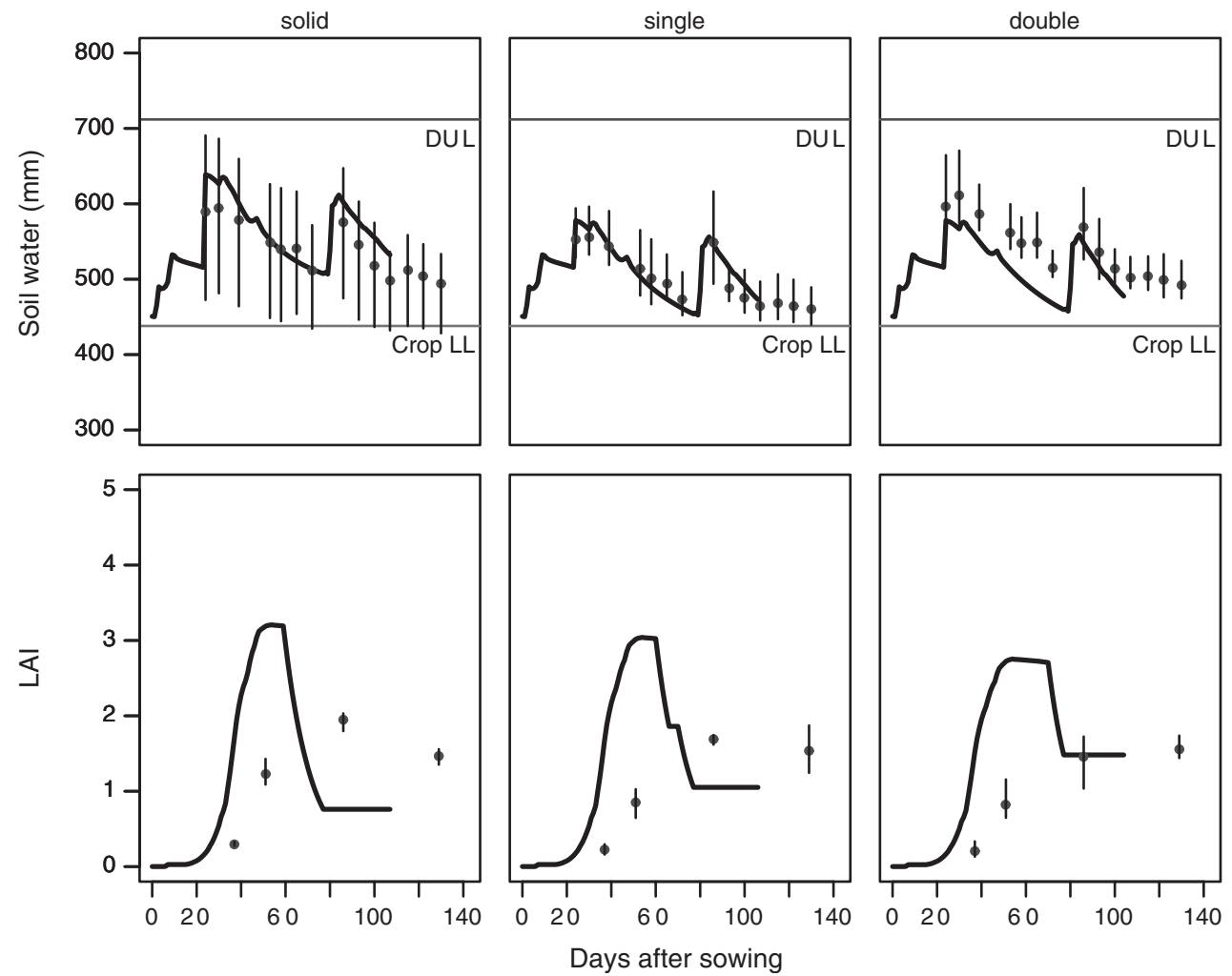

Fig. 3. Observed (points) and simulated (line) soil water and leaf area index (LAI) for solid, single, and double skip configurations at Billa Billa 2001. Horizontal lines indicate crop lower limit (Crop LL) and the soil's drained upper limit (DUL). Vertical bars indicate the range of the observed data points.
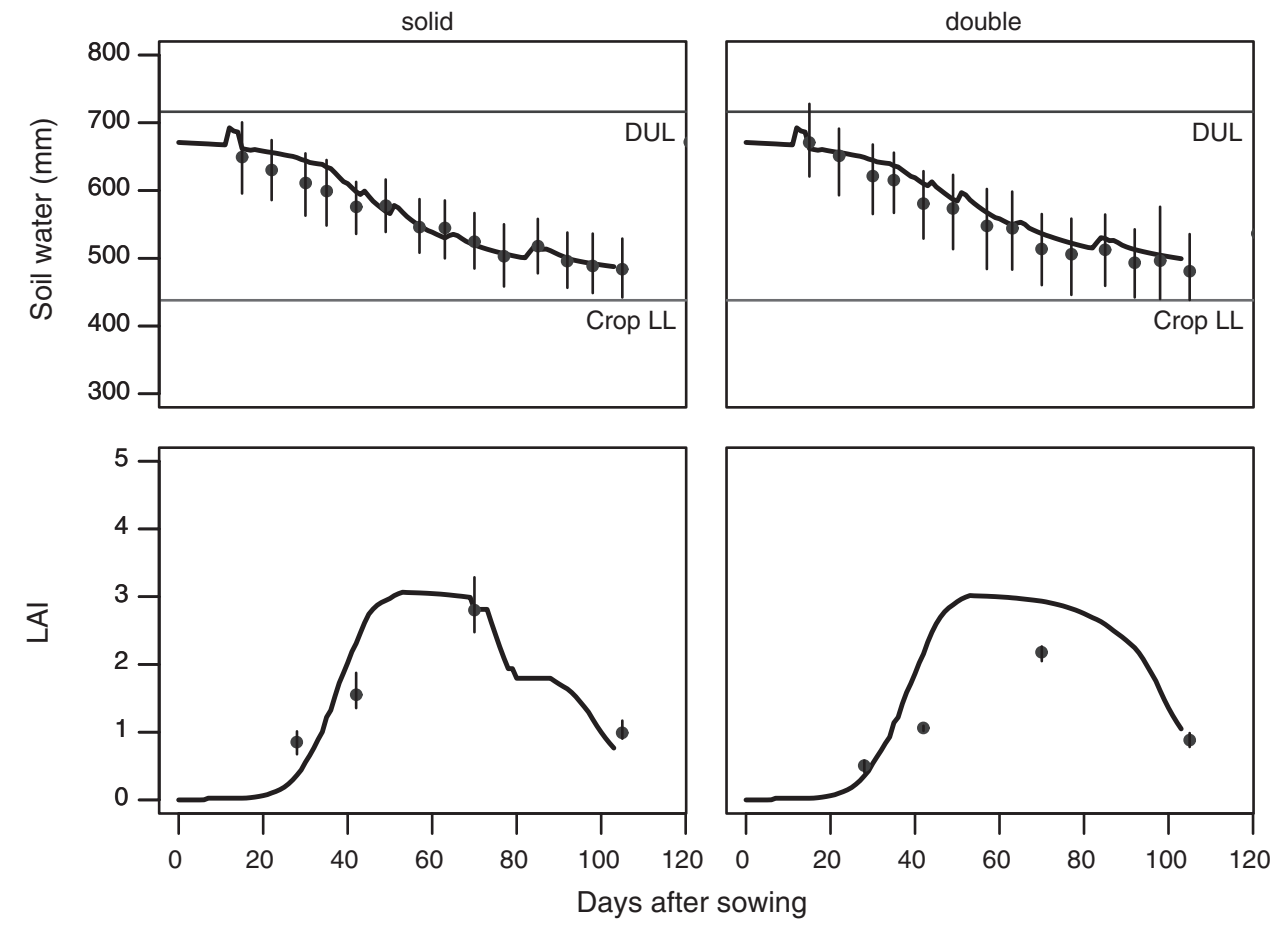

Fig. 4. Observed (points) and simulated (line) soil water and leaf area index (LAI) for solid and double skip configurations at Billa Billa 2002. Horizontal lines indicate crop lower limit (Crop LL) and the soil's drained upper limit (DUL). Vertical bars indicate the range of the observed data points. 

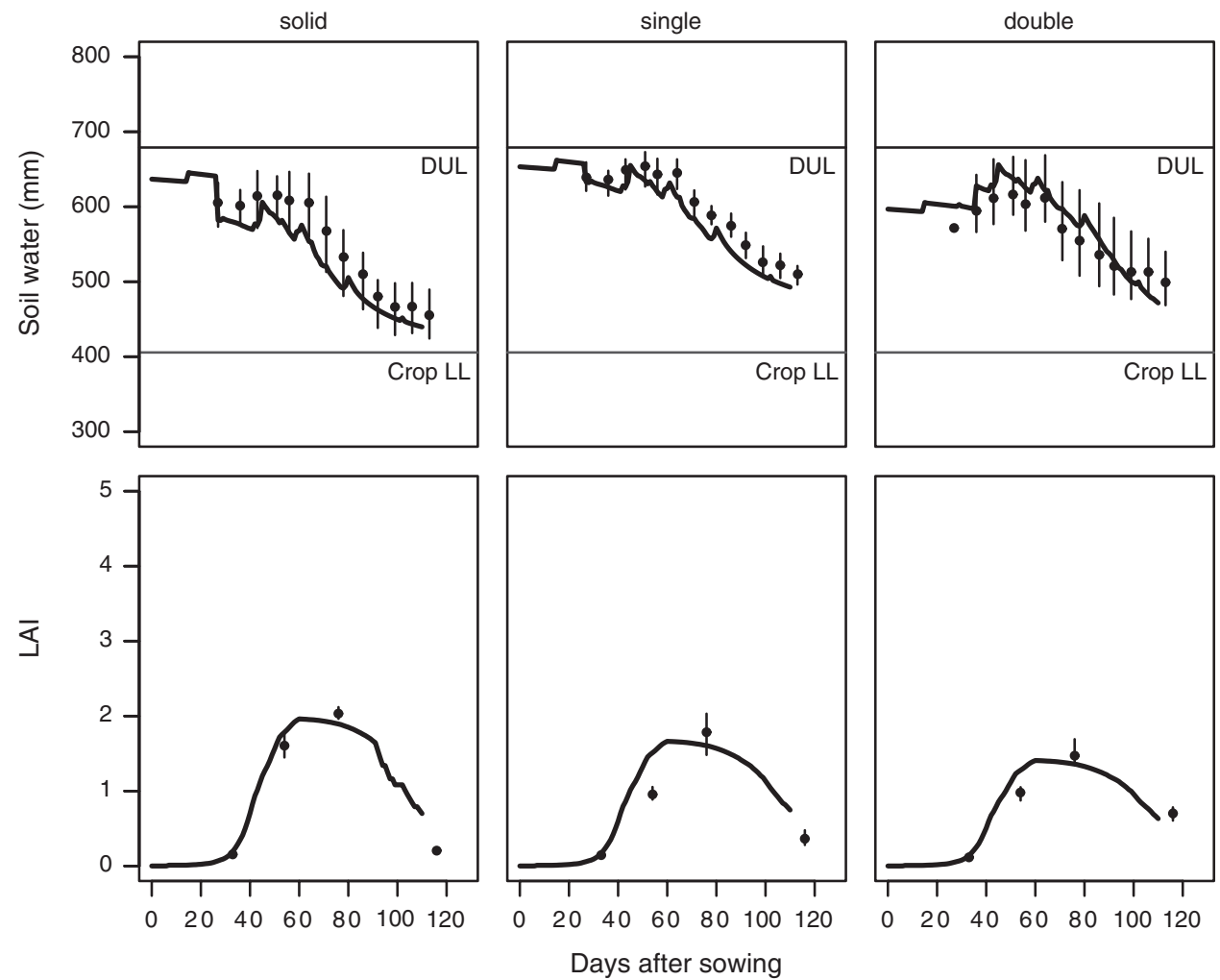

Fig. 5. Observed (points) and simulated (line) soil water and leaf area index (LAI) for solid, single, and double skip configurations at Bungunya 2002. Horizontal lines indicate crop lower limit (Crop LL) and the soil's drained upper limit (DUL). Vertical bars indicate the range of the observed data points.

solid crops $50 \%$ of the time but the long-term average yield is greater for solid crops. This difference occurs because solid crops have a higher yield potential and the magnitude of the difference between solid and skip crops in good seasons is what shifts the long-term average in favour of the solid configuration (Fig. 8).

Production of sorghum in a skip arrangement sacrifices crop yield to reduce the risk of crop failure. Examination of yield probability of exceedence graphs shows a narrow yield range for double skip crops and a broader range for the solid crops from simulations with a PAWC of $200 \mathrm{~mm}$ (Fig. 9). Although there is a significantly reduced chance of exceeding a high yield with double skip crops, there is also significantly greater chance of exceeding low or break-even yield levels. In soils with a PAWC of $130 \mathrm{~mm}$ the differences between the skip treatments and the solid treatment were reduced (Fig. 10). However, the skip treatments never have a failed crop, whereas there were 17 in the solid treatments (Table 4).

\section{Discussion}

The production of sorghum crops in a skip configuration has become an accepted practice in the sorghum-production areas of north-eastern Australia. The motivations for using the skip configuration are based on the crop's physiological responses to early-season competition. These are the key to successfully implementing skip sorghum as a management practice within the farming system. Skip crops are sown at the same $\mathrm{kg} / \mathrm{ha}$ as a solid crop, but the number of rows is reduced. This effectively reduces the intra-row plant spacing and increases the inter-row plant space. This arrangement imposes early stress on the young plants as they compete for resources, which in-turn effects tiller development (Blum and Naveh 1976; Wade et al. 1991), possibly via effects on light quality as well as carbohydrate mobility (Lafarge and Hammer 2002). Skip sorghum plants sown at a medium to high density have fewer tillers compared with crops grown in a solid configuration at the same density. As well as restricting the relative size of the developing canopy, fewer tillers reduce the number of grains to fill late in the season when resources are scarce. If the density selected for the skip crop is too low to impose an early stress, then the value of using a skip configuration may be reduced by compensatory tillering.

Producing crops in a skip configuration results in a discontinuous canopy that can have significant effects on crop yield (Myers and Foale 1981; Holland and McNamara 1982). However, the wider rows do increase the weed management options, with inter-row shielded spraying or cultivation being more easily implemented in the wider rows (Whish et al. 2002). 


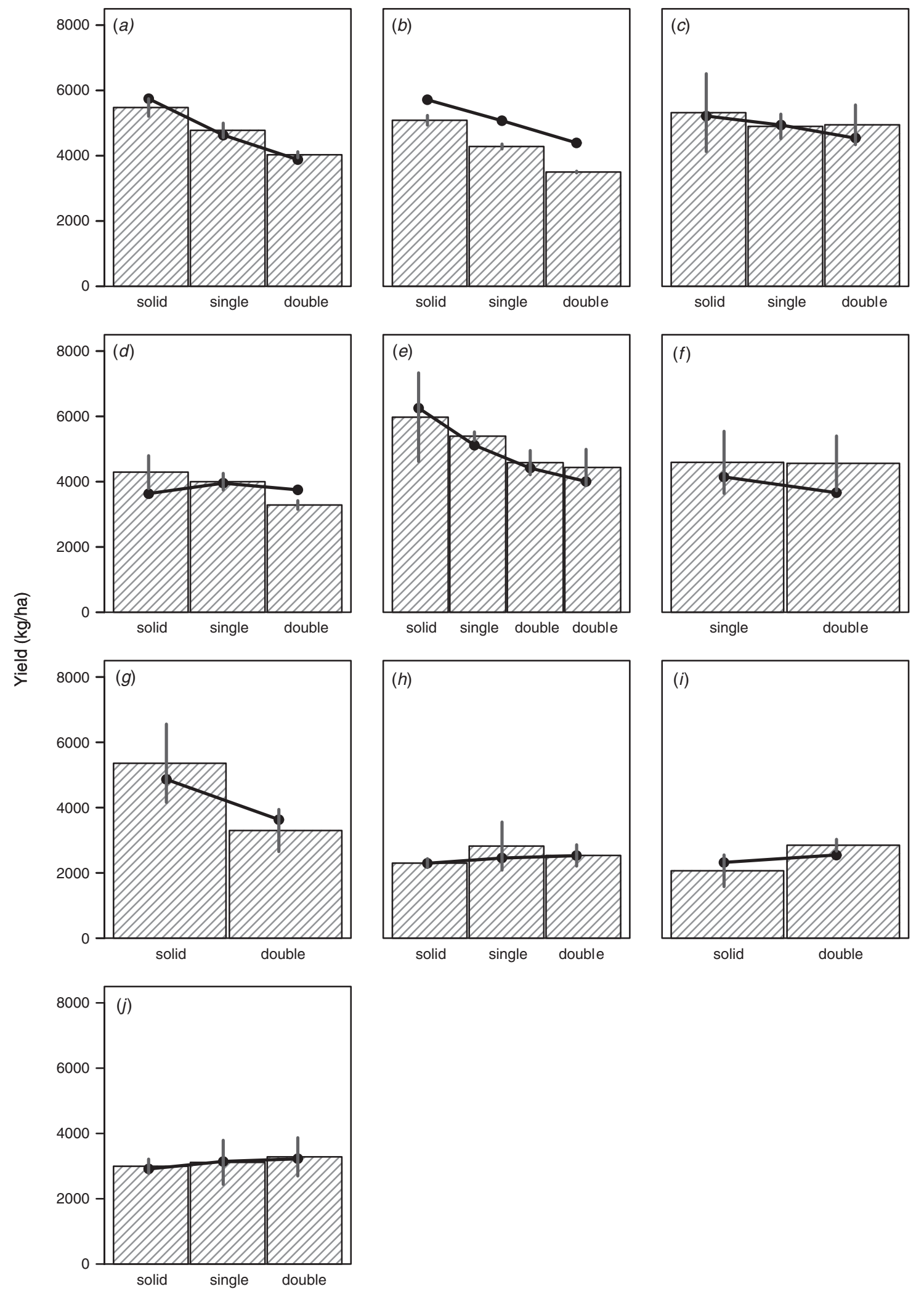

Fig. 6. Observed (bars) and predicted (points) of sorghum yields for 10 commercial sorghum crops grown in solid and skip configurations: (a) Moree 1999, (b) North Star 1999, (c) North Star 2000, (d) Meandarra 1998, (e) Meandarra 1999, (f) Meandarra 2000, (g) Boggabilla 1998, (h) Billa Billa 2000, (i) Billa Billa 2001, (j) Bungunya 2001. Vertical bars through the points show the distribution of observed yields. 
Table 3. Analysis of variance table showing levels of significance for starting water and skip configuration on yield for the long term simulation runs

\begin{tabular}{lccc}
\hline Site & Water & Skip & Water $\times$ Skip \\
\hline Billa Billa & $* * *$ & $* * *$ & $* * *$ \\
North Star & $* * *$ & $* * *$ & $* *$ \\
Bungunya & $* * *$ & $* * *$ & $\dagger$ \\
Moree & $* * *$ & $* * *$ & $\dagger$ \\
Boggabilla & $* * *$ & $* *$ & \\
Meandarra & $* * *$ & $*$ & \\
\hline
\end{tabular}

${ }^{\dagger} P<0.1 ; * P<0.05 ; * * P<0.01 ; * * * P<0.001$.

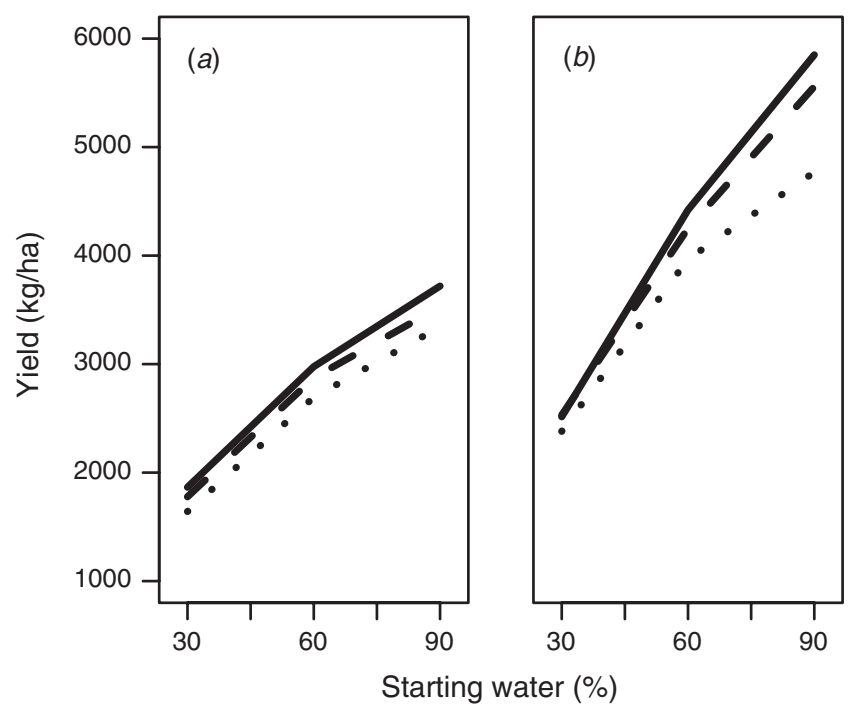

Fig. 7. Average simulated yields at (a) Meandarra (135 m PAWC) and $(b)$ North Star $(238 \mathrm{~mm}$ PAWC) for the 3 skip configurations: solid (__ $)$, single (_ _ $)$, and double (...) at 3 levels of starting soil water $(30,60,90 \%)$.

Greater numbers of farmers in the 1990s and 2000s established crops using zero tillage than did in the 1970s. In the majority of the earlier studies on skip sorghum (reviewed above), crops were not established using zero tillage. Mulch cover in the inter-row may reduce water loss due to evaporation, thereby changing the relative water use patterns. However, in some rotational situations, skip sorghum crops follow cotton or legume crops and this reduces the mulch cover, which increases the potential for soil erosion during the high-intensity, summer storm periods (Loch and Silburn 1997).

Skip configurations can be used within a rotation for a number of purposes. In marginal rainfall areas, skip configurations may extend the range of sorghum production and provide a summer cropping option in areas dominated by winter crops (Routley et al. 2003). In less marginal regions, skip configurations can be used tactically as a means of reducing risk in seasons with a seasonal forecast for belowaverage rainfall or when starting soil water conditions are less than optimal. In rotations that include higher risk summercropping options such as cotton, parallel plantings of skip sorghum can be used to offset risk and maintain cash flow. In these situations, if rainfall is adequate the skip crop will have sacrificed yield, but the surplus soil water remaining after the crop can be used for more profitable double crop options such as chickpea and as a way of switching from summer to winter crops (Whish et al. 2001).

The modifications made to the light interception and water uptake routines in the APSIM sorghum model enabled successful simulation of sorghum crops grown in a skip configuration. The output from the modified model had a high correlation to observed data collected from both on-farm experimental sites and commercial crops (Figs 5 and 6). The APSIM-Sorghum module dynamically simulates crop growth. However, at present the model cannot simulate tiller production dynamically. The number of fertile tillers (i.e. those surviving to produce a head) used in the model is input from observed data. Future improvements to the model will implement dynamic tiller production based on the studies reported by Lafarge and Hammer (2002) and this will enable improved accuracy when simulating density and row configuration interactions. Crop yield, biomass, and water use by the sorghum crop were successfully simulated regardless of row configuration. However, Routley et al. (2003) observed that crop screenings (generally small grain passing through a $2-\mathrm{mm}$ sieve) were greater in solid than in the skip crops in certain situations. Screenings are used as a measure of quality and crops can be downgraded depending on the percentage screenings. The APSIMSorghum module contains algorithms to predict grain size

Table 4. Percentage of the 100 simulated crops successfully reaching maturity for each of the starting water (30, $60,90 \%$ PAWC) and skip (soild, single, double) treatments

\begin{tabular}{|c|c|c|c|c|c|c|c|c|c|}
\hline \multirow[t]{2}{*}{ Site } & \multicolumn{3}{|c|}{$30 \%$ PAWC } & \multicolumn{3}{|c|}{$60 \%$ PAWC } & \multicolumn{3}{|c|}{$90 \%$ PAWC } \\
\hline & Solid & Single & Double & Solid & Single & Double & Solid & Single & Double \\
\hline Billa Billa & 82 & 100 & 100 & 100 & 100 & 100 & 100 & 100 & 100 \\
\hline North Star & 82 & 100 & 100 & 100 & 100 & 100 & 100 & 100 & 100 \\
\hline Bungunya & 83 & 100 & 100 & 96 & 100 & 100 & 100 & 100 & 100 \\
\hline Moree & 75 & 100 & 100 & 100 & 100 & 100 & 100 & 100 & 100 \\
\hline Boggabilla & 83 & 100 & 99 & 95 & 100 & 100 & 100 & 100 & 100 \\
\hline Meandarra & 83 & 100 & 100 & 91 & 100 & 100 & 100 & 100 & 100 \\
\hline
\end{tabular}


Table 5. Percentage of crops where skip configuration out-yielded or equalled solid row configuration for the 3 starting water conditions $(30,60,90 \%$ PAWC) at each site

\begin{tabular}{lcccccc}
\hline \multicolumn{1}{c}{ Skip: } & $30 \%$ & $\begin{array}{c}\text { Double } \\
60 \%\end{array}$ & $90 \%$ & $30 \%$ & $\begin{array}{c}\text { Single } \\
60 \%\end{array}$ & $90 \%$ \\
\hline Billa Billa & 47 & 40 & 17 & 58 & 49 & 39 \\
North Star & 52 & 51 & 31 & 62 & 54 & 49 \\
Bungunya & 44 & 46 & 36 & 56 & 49 & 44 \\
Moree & 61 & 58 & 30 & 68 & 59 & 45 \\
Boggabilla & 42 & 50 & 50 & 49 & 49 & 54 \\
Meandarra & 41 & 46 & 49 & 52 & 52 & 50 \\
\hline
\end{tabular}

but not the distribution of grain size, hence it is not possible to estimate screenings at this time.

\section{Interaction of soil PAWC and proportion of starting water}

The use of double or single skip configuration improves the yield reliability of sorghum by reducing failures (Table 4, Fig. 10; Blum and Naveh 1976; Wade et al. 1991). The longterm simulation analysis highlighted the fact that sorghum yield in the northern cropping region is strongly influenced by starting soil water (Table 3). The skip treatments displayed a significant interaction with the soil water treatments (Table 3 ) for those sites where the soil PAWC was greater than $200 \mathrm{~mm}$. In the shallower soils with lower water-holding capacity, yield of the solid crops was constrained and the potential yield was lower, reducing the difference between solid and skip configurations.

The initial starting water is a good indicator as to how risky crop production will be in a specific year. Long-term simulations showed that if the soil has a PAWC of greater than
$200 \mathrm{~mm}$ and the profile is $90 \%$ full, the risk of a failed crop is low, and a solid configuration will maximise yield potential with minimal risk. On the shallower soils with a $90 \%$ starting moisture, the risk of crop failure is also low, but the yield potential of a solid configuration is not substantially greater than for the skip configuration. In this situation the potential yield loss by choosing a skip configuration is far less than for a higher PAWC soil.

Starting the soil with a $30 \%$ full profile significantly reduced the yield potential for both solid and skip configurations (Fig. 7). On the higher PAWC soil the skip configurations were dominant with yields of approximately $2.5 \mathrm{t} / \mathrm{ha}$, there was then a yield interval between 2.5 and $5 \mathrm{t} / \mathrm{ha}$ in which the solid and single skip configurations out-yielded the double skip crop. The solid crop was dominant for $10 \%$ of the time at yield levels in excess of $5 \mathrm{t} / \mathrm{ha}$ (Fig. 9). The differences between the skip and the solid configuration under low starting water conditions were smaller, except at the extremes of the yield distribution (Fig. 10). Notably, however,

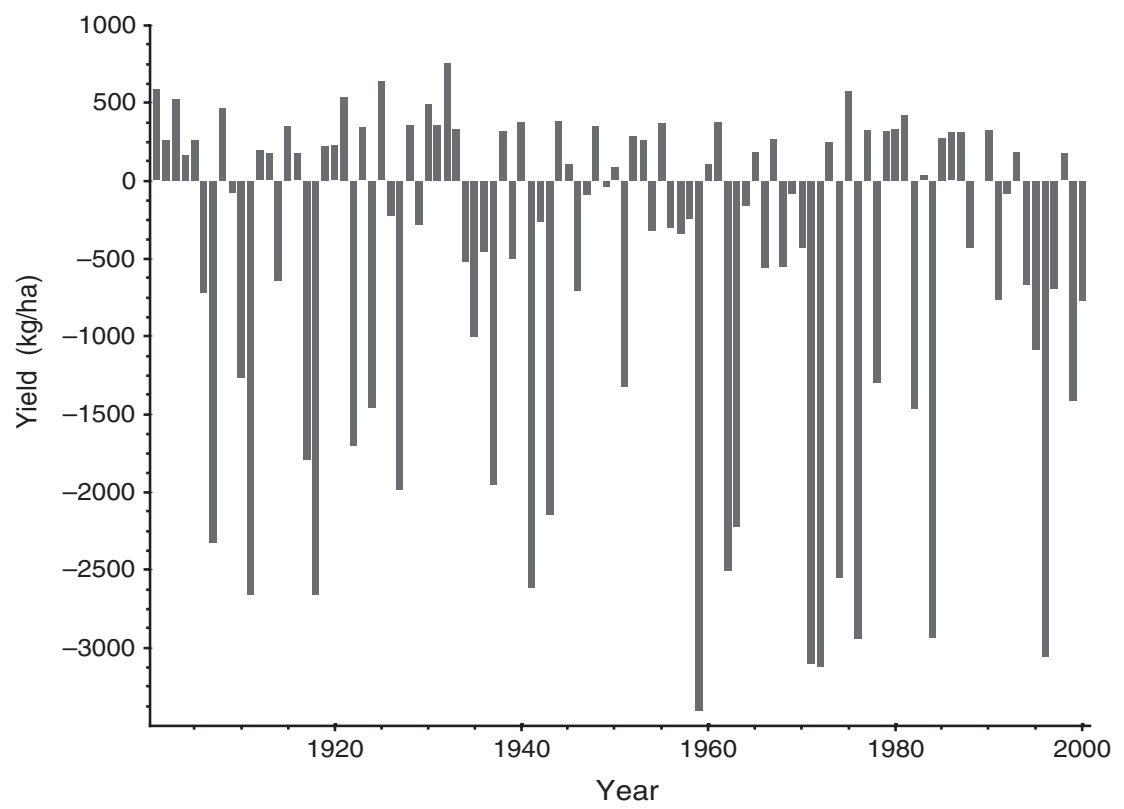

Fig. 8. Yield difference plot (double skip, solid) for $60 \%$ starting water $(\mathrm{PAWC}=202 \mathrm{~mm}$ ) at Bungunya. Columns above the line occur when skip yield is greater than solid, and negative yields are when solid is greater than skip. 


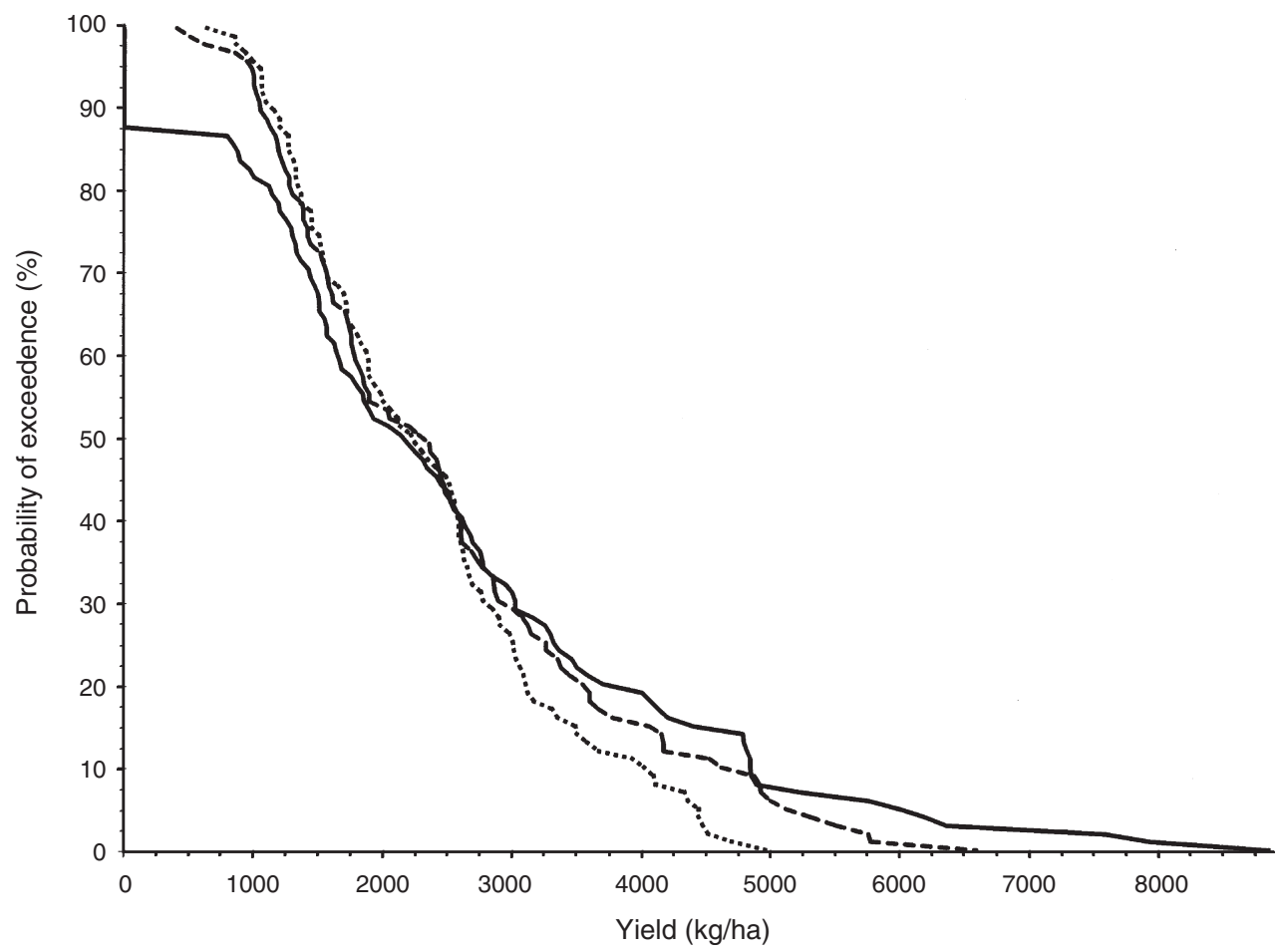

Fig. 9. Probability of exceedence for simulated crop yields with 3 row configurations: solid (_), single ( _ _ ), double (. . . .) skip, at Croppa Creek with a starting water of $30 \%$ PAWC.

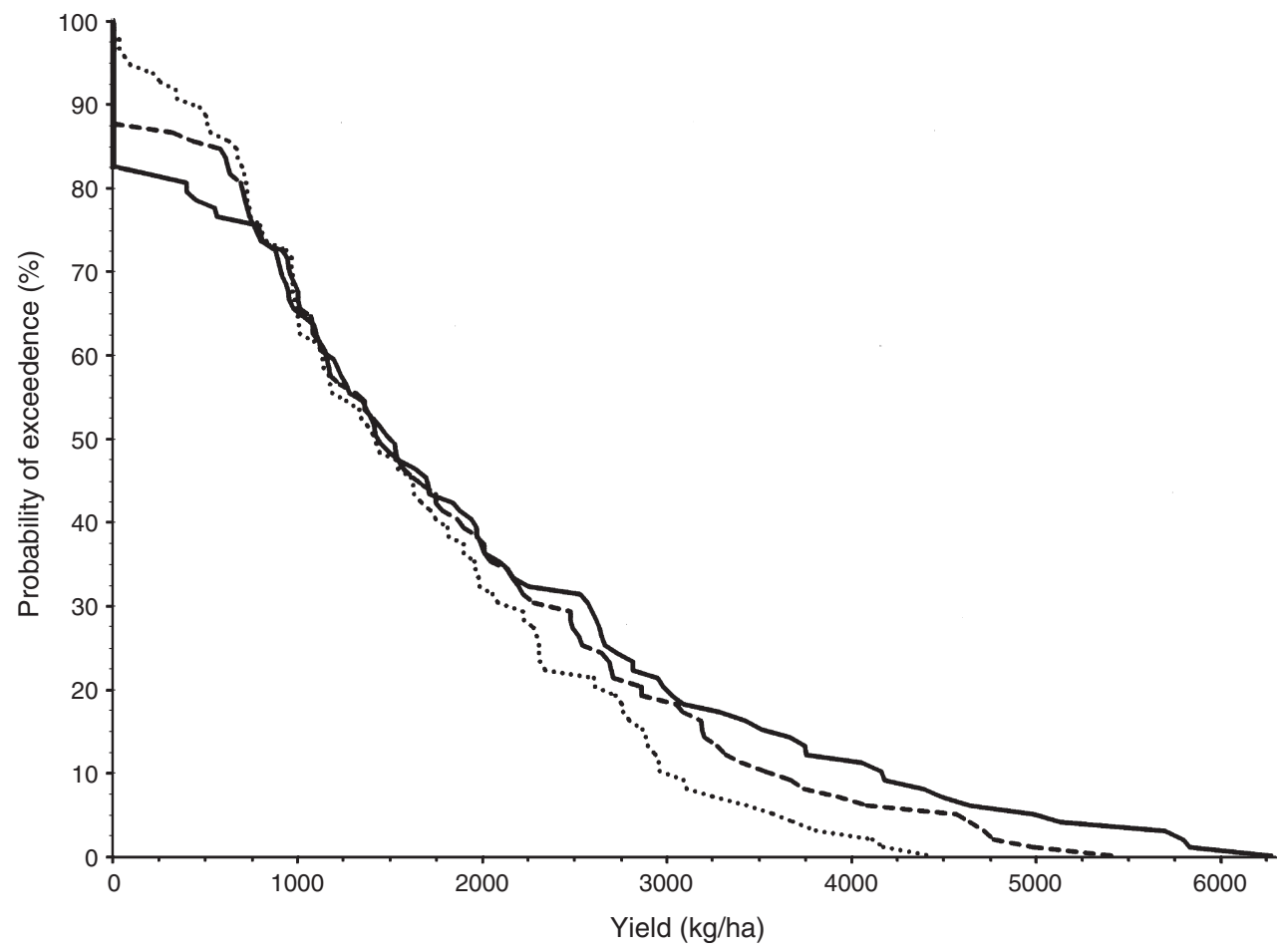

Fig. 10. Probability of exceedence for simulated crop yields with 3 row configurations: solid (_), single ( _ _ ), double (. . . .) skip, at Meandarra with a starting water of 30\% PAWC. 
the difference in successful crops was large with 17 (approx. 1 in 5) solid crops failing.

Knowledge of the potential soil water-holding capacity (PAWC) and of the current soil water status is a useful guide in deciding what row configuration to use in a particular year. In some situations, seasonal climate forecasts based on the phase of the SOI (Southern Oscillation Index; Stone et al. 1996) can add value to the soil water information in guiding risky decisions (Hammer et al. 1996). In the cases examined in this paper, however, while the forecast influenced yield level, it did not affect the relative distributions among skip configurations (data not presented).

Blum and Naveh (1976) and Wade et al. (1991) discuss the merit of using row spacing as a means of avoiding risk in climatically variable environments. This approach works because the high plant densities within the row advance the onset of inter-plant competition, reducing early leaf area development and tillering and possibly root growth. If the density of plants within the crop row is low or the distribution of plants along the row is uneven or clumped, this will cause irregular responses of the plant to its environment (Wade et al. 1991) and reduce the benefits of imposed spatial arrangements. The use of precision planters has greatly improved the uniformity of many sorghum crops and increased the success of sorghum grown in skip row configurations (Butler et al. 2001; Routley et al. 2003).

\section{Conclusions}

The results from the simulation studies discussed in this paper offer some insight as to the consequences of each row configuration for the situations studied. However, the decision as to what configuration to use will depend on the individual farmer's position on risk. Solid configurations were more risky than skip configurations, but on average provided the highest yield (Fig. 7). Increases in soil starting water and knowledge of the soil's PAWC help reduce the risk of crop failure (Table 4), and identify the potential yield sacrifice associated with skip configurations in good seasons. In some circumstances, it may be important to reduce the risk of one summer crop, to offset other summer crops that may be more risky yet potentially more profitable. In some farming systems, maintaining the rotation sequence is important, and the use of skip sorghum is one way to move between summer and winter crops (Whish et al. 2001), without wasting stored water, but maintaining a positive cash flow.

In conclusion, the modifications to the APSIM-Sorghum module enable the model to accurately simulate both experimental and commercial skip row crops in the sorghum-growing regions of northern NSW and southern Qld. The successful validation of the sorghum model on field data, lends weight to the validity of the longterm simulations that show that the choice to use a skip configuration, in the situations analysed, is best based on knowledge of the soil PAWC and starting water. However, ultimately, the key factor is the farmer's adversity to risk in each season.

The results described in this paper have focussed on the inclusion of skip row configurations in relation to the sorghum crop in situations relevant to those sampled in on-farm studies. Future work will look at how skip sorghum can be used in more diverse situations and as a tactic within a rotation to reduce risk, both in marginal areas and in combination with high-value, high-risk crops, and as a mechanism to move between summer and winter crops.

\section{Acknowledgments}

We thank members of the Eastern Farming Systems Project and the reviewers for their comments.

Support from the Grains Research and Development Corporation is duly acknowledged.

\section{References}

Blum A, Naveh M (1976) Improved water-use efficiency in dryland grain sorghum by promoted plant competition. Agronomy Journal 64, 775-778.

Butler GJ, Cawthray S, Castor M, Yeates S, Christian T (2001) Improving the reliability of sorghum production in the farming system. In 'Proceedings of the 10th Australian Agronomy Conference'. Hobart, Tas. (The Australian Society of Agronomy)

Carberry PS, Abrecht DG (1991) Tailoring crop models to the semi arid tropics. In 'Climatic risk in crop production: models and management for the semi-arid tropics and subtropics'. (Eds RC Muchow, JA Bellamy) pp. 157-182. (CAB International: Wallingford, UK)

Charles-Edwards DA, Lawn RJ (1984) Light interception by grain legume row crops. Plant, Cell and Environment 7, 247-251.

Dalgliesh N, Foale M (1998) 'Soil matters: monitoring soil water and nutrients in dryland farming.' Technical Manual. (CSIRO/Agricultural Production Systems Research Unit: Toowoomba, Qld)

Foale MA, Coates DB (1980) Yield of two grain sorghum cultivars at four populations. Sorghum Newsletter 23, 46.

Fukai S, Foale MA (1988) Effects of row spacing on growth and grain yield of early and late sorghum cultivars. Australian Journal of Experimental Agriculture 28, 771-777.

Hammer GL, Carberry PS, Muchow RC (1993) Modelling genotypic and environmental control of leaf area dynamics in grain sorghum. I. Whole plant level. Field Crops Research 33, 293-310. doi: 10.1016/0378-4290(93)90087-4

Hammer GL, Holzworth DP, Stone R (1996) The value of skill in seasonal climate forecasting to wheat crop management in a region with high climatic variability. Australian Journal of Agricultural Research 47, 717-737. doi: 10.1071/AR9960717

Hammer GL, Muchow RC (1991) Quantifying climatic risk to sorghum in Australia's semiarid tropics and subtropics: Model development and simulation. In 'Climatic risk in crop production: models and management for the semi-arid tropics and subtropics'. (Eds RC Muchow, JA Bellamy) pp. 205-232. (CAB International: Wallingford, UK)

Holland JF, McNamara DW (1982) Weed control and row spacing in dry-land sorghum in northern New South Wales. Australian Journal of Experimental Agriculture and Animal Husbandry 22, 310-316. 
R Development Core Team (2004) 'R: A language and environment for statistical computing.' URL: http://www.R-project.org. (R Foundation for Statistical Computing: Vienna, Austria)

Jackson JE, Palmer JW (1979) A simple model of light transmission and interception by discontinuous canopies. Annals of Botany 44, 381-383.

Keating BA, Carberry PS, Hammer GL, Probert ME, Robertson MJ, et al. (2003) An overview of APSIM, a model designed for farming systems simulation. European Journal of Agronomy 18, 267-288. doi: 10.1016/S1161-0301(02)00108-9

Lafarge TA, Hammer GL (2002) Tillering in Grain Sorghum over a wide range of population densities: Modelling dynamics of tiller fertility. Annals of Botany 90, 99-110. doi: 10.1093/AOB/MCF153

Loch RJ, Silburn DM (1997) Constraint to sustainability — soil erosion. In 'Sustainable crop production in the sub-tropics: an Australian perspective'. (Eds AL Clarke, PB Wylie) pp. 27-41. QDPI Monograph, Information Series QI97035. (Queensland Department of Primary Industries: Brisbane)

McLean G, Whish J, Routley RA, Broad I, Hammer GL (2003) The effect of row configuration on yield reliability in grain sorghum. II. Modelling the effects of row configuration. In 'Proceedings of the 11th Australian Agronomy Conference'. Geelong, Vic. (The Australian Society of Agronomy)

Myers RJK, Foale MA (1981) Row spacing and population density in grain sorghum - a simple analysis. Field Crops Research 4, $146-154$.

Myers RJK, Foale MA, Thomas GA, French AV, Hall B (1986) How row spacing affects water use and root growth of grain sorghum. In 'Proceedings of the 1st Australian Sorghum Conference'. Gatton, Qld. (Eds MA Foale, RG Henzell) pp. 5-86. (Queensland Branch of Australian Institute of Agricultural Science: Brisbane, Qld)

Phillips LJ, Norman MJT (1962) The influence of inter-row and intra-row spacing on the yield of grain sorghum at Katherine, NT. Australian Journal of Experimental Agriculture and Animal Husbandry 2, 204-208.

Robertson MJ, Fukai S (1994) Comparison of water extraction models for grain sorghum under continuous soil drying. Field Crops Research 36, 145-160. doi: 10.1016/0378-4290(94)90063-9
Routley RA, Broad I, McLean G, Whish J, Hammer GL (2003) The effect of row configuration on yield reliability in grain sorghum. I. Yield, water use efficiency and soil water extraction. In 'Proceedings of the 11th Australian Agronomy Conference'. Geelong, Vic. (The Australian Society of Agronomy)

Stone RC, Hammer GL, Marcussen T (1996) Prediction of global rainfall probabilities using phases of the Southern Oscillation Index. Nature 384, 252-255. doi: 10.1038/384252A0

Thomas GA, Myers RJK, Foale MA, French AV, Hall B, et al. (1981) Evaluation of row spacing and population density on grain sorghum over a range of northern Australian environments. Australian Journal of Experimental Agriculture and Animal Husbandry 21, 210-217.

Wade LJ, Douglas ACL (1990) Effect of plant density on grain yield stability of sorghum hybrids differing in maturity. Australian Journal of Experimental Agriculture 30, 257-264.

Wade LJ, Myers RJK, Foale MA (1991) Optimising plant stand in response to climatic risk. In 'Climatic risk in crop production: models and management for the semi-arid tropics and subtropics'. (Eds RC Muchow, JA Bellamy) pp. 263-282. (CAB International: Wallingford, UK)

Wang E, Robertson MJ, Hammer GL, Carberry PS, Holzworth D, Meinke H, Chapman SC, Hargreaves JNG, Huth NI, McLean G (2002) Development of a generic crop model template in the cropping system model APSIM. European Journal of Agronomy 18, 121-140. doi: 10.1016/S1161-0301(02)00100-4

Whish JPM, Butler GJ, Cawthray S, Castor M, Carberry PS (2001) Manipulating sorghum row configuration to benefit double cropping opportunities. In 'Proceedings of the 4th Australian Sorghum Conference'. Kooralbyn Hotel. (Eds AK Borrell, RG Henzell). (Queensland Branch of Australian Institute of Agricultural Science: Brisbane)

Whish JPM, Sindel BM, Jessop RS, Felton WL (2002) The effect of row spacing and weed density on yield loss of chickpea. Australian Journal of Agricultural Research 53, 1335-1340. doi: 10.1071/AR01168

Manuscript received 11 June 2004, accepted 11 November 2004 